\title{
Avaliação da densidade óssea da mandíbula e fêmur de camundongos suplementados com vitamina D
}

Raphael Henrique PALCZEWSKI'; Danielle Shima LUIZE'; Adair Santa CATARINA2; Adriane Yaeko TOGASHI ${ }^{1}$

1 - Universidade Estadual do Oeste do Paraná, Centro de Ciências Biológicas e da Saúde, Programa de Pós-Graduação em Odontologia, Cascavel, Paraná, Brasil; 2 - Universidade Estadual do Oeste do Paraná, Centro de Ciências Exatas, Programa de Pós-Graduação em Ciências da Computação, Cascavel, Paraná, Brasil.

\section{Resumo}

Objetivo: Este estudo experimental foi realizado com o objetivo de avaliar a influência da suplementação de vitamina D3 (VitD) sobre a densidade óssea do fêmur e mandíbula de camundongos. Material e Métodos: Camundongos C57BL/6 foram utilizados e divididos em dois grupos: 1) grupo controle e 2) grupo VitD - submetidos à administração sistêmica de vitamina D3 na concentração de 10.000 UI por semana durante 4 semanas, por meio de gavagem. Após 4 semanas da administração da VitD, cirurgia de instalação de implante de titânio foi realizada na região lateral da mandíbula dos animais. E após 7 e 21 dias da colocação dos implantes, as radiografias periapicais digitais da mandíbula e das regiões de metáfise e diáfise femoral foram analisadas pelo programa BmA-DDX, a fim de se verificar a contagem de pixels trabeculares. Para a análise estatística foram aplicados os testes Anova e correlação múltipla de Bonferroni. Resultados: Os resultados da análise radiográfica demonstraram que na mandíbula houve aumento na densidade óssea no grupo VitD em relação ao grupo controle $(\mathrm{p}<0,05)$, não havendo, entretanto, diferença no mesmo grupo ao longo do tempo. Na região de metáfise do fêmur não houve diferença entre os grupos ao longo do tempo, porém, na região de diáfise notou-se um aumento no número de pixels trabeculares no grupo suplementado com VitD em comparação ao grupo controle $(\mathrm{p}=0,001)$. Conclusões: Pode-se sugerir que na mandíbula ao redor do implante e diáfise femoral avaliadas pela análise radiográfica digital, a suplementação com VitD indicou um aumento na densidade óssea.

PALAVRAS-CHAVE: Camundongos. Densidade Óssea. Radiografia Dentária. Suplementos Nutricionais. Vitamina D.

\section{AUTOR PARA CORRESPONDÊNCIA}

Adriane Yaeko Togashi

Rua Universitária, 2069 - Jd. Universitário, Cascavel-PR, Brasil, CEP: 85.814-110

E-mail: adriane.togashi@unioeste.br

Telefone: (45) 9 8808-6868 


\section{Introdução}

A vitamina $\mathrm{D}$ (VitD) desempenha um papel importante na modulação da homeostase do cálcio esquelético e exerce uma influência significativa sobre o crescimento e diferenciação de uma variedade de tecidos ${ }^{1,2}$ e tem sido amplamente utilizada para a prevenção e tratamento da osteoporose. Contudo as pesquisas sobre o efeito da vitamina $\mathrm{D}$ na melhora da osseointegração e cicatrização óssea dos implantes dentários são pouco descritas ${ }^{3,4}$. O estudo de Kelly et al. ${ }^{3}$ (2009) encontrou uma significativa redução na osseointegração em ratos machos insuficientes de VitD, porém Alvim-Pereira et al. ${ }^{4}$ (2008) não encontrou uma relação entre o polimorfismo no receptor de vitamina $\mathrm{D}$ (VDR) e perda de implantes dentários, o que demonstra que o efeito da VitD sobre a osseointegração e cicatrização em enxertos ósseos ainda não foi esclarecida. A qualidade óssea da mandíbula é de fundamental importância para o sucesso da osseointegração dos implantes dentários e a literatura científica ainda é insuficiente para esclarecer se a diminuição da densidade óssea sistêmica identificada em exames de imagem da coluna lombar e fêmur indicam que, de fato, ocorra também diminuição da densidade no osso mandibular. Este questionamento se deve ao fato de que a mandíbula apresenta um distinto processo de ossificação em relação ao fêmur e coluna vertebral.

O mecanismo do efeito da VitD no osso ainda é controverso e pode ser reconhecido como um agente de reabsorção óssea em estudos in vitro ${ }^{5,6}$, contudo estudos clínicos e em animais ${ }^{7} \mathrm{de}-$ monstraram que a mesma inibe osteoclastogênese através de interferon- $\beta$-dependente das células $\mathrm{T}$ ativadas e indicaram que a VitD exerce um efeito protetor sobre o osso independente dos seus efeitos estarem relacionados com o cálcio e a supressão de paratormônio. Os estudos em animais utilizando modelos de fratura indicaram que a vitamina $\mathrm{D}$ pode aumentar a resistência óssea ${ }^{8}$ por meio de sua atividade sobre as células osteoblásticas e trabeculado ósseo com consequente aumento de sua densidade mineral em concentrações adequadas ${ }^{9}$. 
Porém, nos casos de insuficiência da VitD observou-se um aumento na diferenciação dos osteoclastos imaturos em maduros com maior absorção óssea, devido ao aumento da concentração de paratormônio promovendo maior expressão de RANKL (ligante do receptor do fator nuclear-kB) sobre a superfície dos osteoclastos ${ }^{10}$, pois a mesma é absorvida a partir da dieta e também gerada pela pele durante exposição à luz ultravioleta, podendo ter sua produção limitada por fatores como idade, pele pigmentada, uso de protetor solar e roupas, necessitando em muitos casos a suplementação via oral.

A vitamina D3 ou colecalciferol é hidroxilada no fígado em 25-di-hidroxivitamina D3 (25D) e, subsequentemente, no rim em 1,25-di-hidroxivitamina D3 (1,25D), sendo este o metabólito ativo, que estimula a absorção de cálcio a partir do intestino ${ }^{11}$. O metabólito ativo de 1,25D entra na célula e liga-se ao VDR formando um heterodímero com o receptor retinóide e liga-se a um elemento de resposta à vitamina $\mathrm{D}$ em um gene responsivo, tais como a osteocalcina, seguido por transcrição e tradução e as proteínas são formadas, onde a 1,25D atuará no transporte ativo de cálcio na célula intestinal, com ajuda de proteínas de membrana. $\mathrm{Na}$ célula intestinal, 1,25D liga-se ao VDR e a proteína de ligação do cálcio onde irá regular o transporte ativo através da célula. $O$ cálcio é transportado para o fluido extracelular por um mecanismo dependente de ATP. Há também o transporte passivo através da difusão de cálcio. A absorção de cálcio com vitamina $\mathrm{D}$ independente, através de difusão passiva não tem um máximo, mas depende do gradiente de cálcio, sendo significativo na ingestão de cálcio ${ }^{11-13}$.

A literatura ${ }^{14-18}$ tem apresentado dados consistentes da influência positiva da vitamina $\mathrm{D}$ nos modelos de estudo em animais roedores, indicando uma ação anabólica direta da vitamina $\mathrm{D}$ em tecido ósseo. Os modelos geneticamente modificados de roedores que consiste na remoção total da vitamina $\mathrm{D}$ ou inativação do receptor de vitamina $D$ têm fornecido fortes evidências 
do envolvimento da vitamina D na manutenção das concentrações de cálcio no plasma e na homeostase de fosfato e a sua relação entre a hipocalcemia e hipofosfatemia ${ }^{13}$. Os dados suportam o conceito de que a atividade da vitamina $\mathrm{D}$ é necessária para manter a mineralização óssea, devido à produção de osteoblastos e para a atividade funcional dos mesmos ${ }^{19}$. Os estudos associados ou não a outros nutrientes como cálcio e fosfato, em modelos de roedores com restrição ou isenção de vitamina $\mathrm{D}$ na dieta, também demonstraram marcada redução dos níveis séricos de 25-hidroxivitamina D em estrutura óssea. Quando as concentrações de 25-hidroxivitamina $\mathrm{D}$ no soro foram reduzidos de $100 \mathrm{nmol} / \mathrm{L}$ para 20 ou $45 \mathrm{nmol} / \mathrm{L}$, durante 3 meses, detecta-se uma indução significativa do ativador do receptor do ligante do fator nuclear kappa (RANKL) dentro do tecido ósseo. Esta redução foi associada com o aumento no número de osteoclastos, com consequente redução no trabeculado ósseo em vários locais do esqueleto, incluindo os fêmures e as vértebras ${ }^{15,20}$.

Diante dessas evidências científicas do mecanismo da vitamina $\mathrm{D}$ e poucos estudos que avaliem, radiograficamente, a densidade óssea, o objetivo deste estudo experimental foi avaliar a influência da suplementação de VitD em camundongos, sobre a estrutura óssea na região lateral da mandíbula submetida à instalação de implante de titânio, e as regiões de metáfise e diáfise do fêmur dos mesmos camundongos.

\section{Material e métodos}

\section{Modelo animal e delineamento}

Camundongos adultos da linhagem C57BL/6 (WT) com idade variando entre 8 a 10 semanas de idade, com peso entre 20 a 30 gramas foram mantidos em temperatura ambiente média de $25^{\circ}$ C com iluminação artificial variando de 5-60 luz; fotoperíodo 12 horas claro e 12 horas escuro, período de luz das $7 \mathrm{~h}$ às $19 \mathrm{hs}$ e sistema de exaustão por aproximadamente 15 trocas de ar/h com umidade relativa de 45 a $75 \%$. 
Todos os animais foram provenientes do Biotério Central da UNIOESTE e com a devida aprovação pelo Comitê de Ética no Uso de Animais (CEUA - UNIOESTE, parecer n 25/2015 e 05/2016).

Os animas foram distribuídos nos seguintes grupos: GC/7: Grupo Controle, 7 dias ( $\mathrm{n}=12$ ); GC/21: Grupo Controle, 21 dias (n=12); GVitD/7: Grupo Vitamina D, 7 dias (n=12) e GVitD/21: Grupo Vitamina D, 21 dias $(\mathrm{n}=12)$.

\section{Administração da vitamina D}

A vitamina $\mathrm{D}$ foi administrada apenas nos animais dos grupos vitamina D (GVit/7 e GVit/21) por via de gavagem, em uma dosagem de $500 \mu \mathrm{L}$ de vitamina D3 $(10.000 \mathrm{UI} / 500 \mu \mathrm{L})$, diluída em óleo de girassol, uma vez por semana, durante o período de 4 semanas de suplementação. Os animais dos grupos controles (GC/7 e GC/21) receberam a gavagem de óleo de girassol puro pelo mesmo período e na mesma quantidade que o grupo VitD.

Todos os animais foram pesados em balança de semiprecisão semanalmente, imediatamente antes de receberem o suplemento de vitamina D3 diluído em óleo de girassol ou óleo puro pela gavagem, durante um período de cinco semanas.

\section{Procedimento cirúrgico}

Após o período de suplementação, todos os animais foram submetidos ao procedimento cirúrgico de colocação de implantes de titânio na região da mandíbula, realizado sob anestesia por injecção de uma combinação de cloridrato de quetamina $(80 \mathrm{mg} /$ $\mathrm{kg}$ ) e xilazina (10 mg $/ \mathrm{kg})$, via injecções subcutâneas.

Primeiramente, fez-se a tricotomia na porção lateral da mandíbula bilateralmente, seguida de desinfecção com clorexidina $2 \%$. Fez-se uma incisão horizontal (com lâmina 11) sobre a área tricotomizada seguida de divulsão e descolamento de pele e músculos para expor a região de corpo e ramo mandibular. 
Realizou-se a perfuração da mandíbula com broca de perfuração, seguido da colocação do implante de titânio comercialmente puro, grau quatro, cilíndrico, com $1 \mathrm{~mm}$ de diâmetro e $3 \mathrm{~mm}$ de comprimento (Figura 1), os quais foram preparados, esterilizados e fornecidos pelo fabricante do Sistema de Implantes Kopp $^{\circledR}$. Em seguida, foi realizado o reposicionamento da musculatura e da pele sobre a região operada e devidamente suturada com fio de nylon 5-0. No pós-operatório imediato, o analgésico paracetamol foi diluído na água dos bebedouros $(10 \mathrm{mg} / \mathrm{ml})$ para minimizar o sofrimento e a dor, sendo mantido por 24 horas.

Após os períodos de 7 e 21 dias da colocação dos implantes na região ramo da mandíbula, os camundongos foram anestesiados com quetamina/xilazina e a eutanásia realizada por sobredose de anestésico.

\section{Análise sorológica de VITD}

As amostras de sangue foram coletadas e processadas em centrífuga (HEMLE Z216 $\mathrm{MR}^{\circledR}$ ) por 10 minutos à $4^{\circ} \mathrm{C}$ de temperatura com velocidade de $8.000 \mathrm{rpm}$, seguida de pipetagem do plasma no momento da eutanásia. E os níveis séricos de $25(\mathrm{OH}) \mathrm{VD}$ foram verificados pelo teste quantitativo VIDAS ${ }^{\circledR}$ $25 \mathrm{OH}$ TOTAL (VITD) com leitura obtida pelo aparelho VITROS ${ }^{\circledR} 4600$ (Gráfico 1).

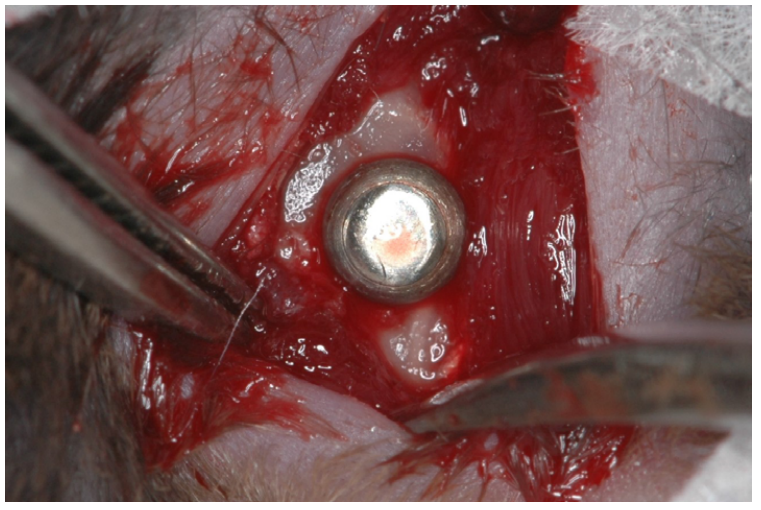

FIGURA 1 - Instalação do implante na mandíbula do camundongo

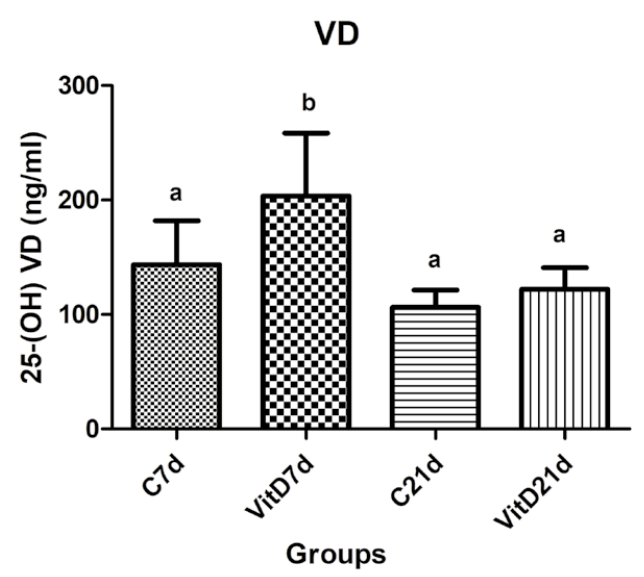

GRÁFICo 1 • Valores médios dos níveis séricos de 25(OH) VD dos grupos controle e VitD 
Preparo das amostras e análise radiográfica digital Após todas as eutanásias, os fêmures e mandíbulas com a retirada dos implantes foram armazenados em formol 10\% e submetidos à radiografia digital dentro de um prazo de 24 horas.

As imagens radiográficas de fêmur e mandíbula obtidas dos 48 animais foram analisadas por meio de um estudo cego.

As amostras foram radiografadas por meio do sensor digital snapshot Instrumentarium ${ }^{\circledR}$, onde foram posicionados 1 par de fêmures e 1 par de mandíbulas de cada grupo (Figura 2). Os fêmures e as mandíbulas tiveram tempo de exposição de 0,3 segundos (70 $\mathrm{Kv}$ e $10 \mathrm{~mA}$ ) a uma distância interfocal de $30 \mathrm{~cm}$, através do aparelho de raios-x da Dabi Atlante ${ }^{\circledR} 70 X$ Classe I - Tipo B comum.
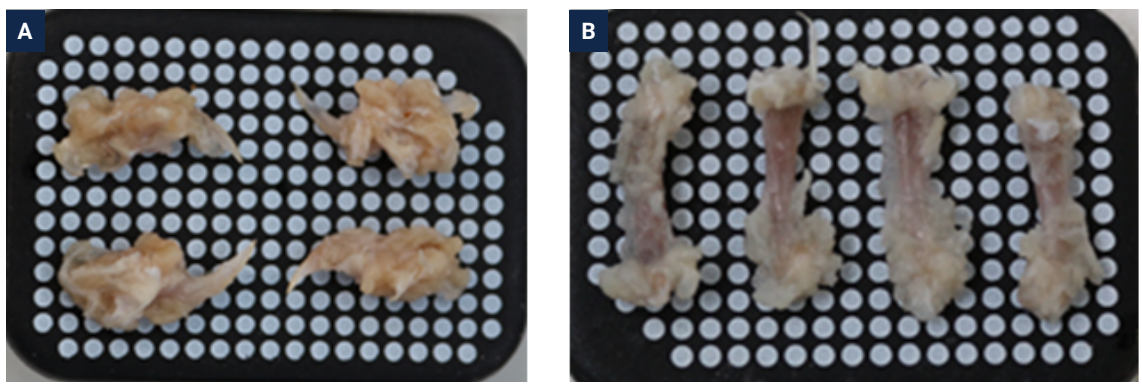

FIGURA 2 - Posicionamento das mandíbulas (A) e dos fêmures (B) sobre sensor digital

Para análise da imagem radiográfica, foi utilizado o software BmA-DDX - Bone Microarchitecture by Dentistry Digital X-RAY - Sistema para Avaliação da Microarquitetura óssea através da radiografia odontológica digital ${ }^{21-23}$ (Figuras 3 e 4).

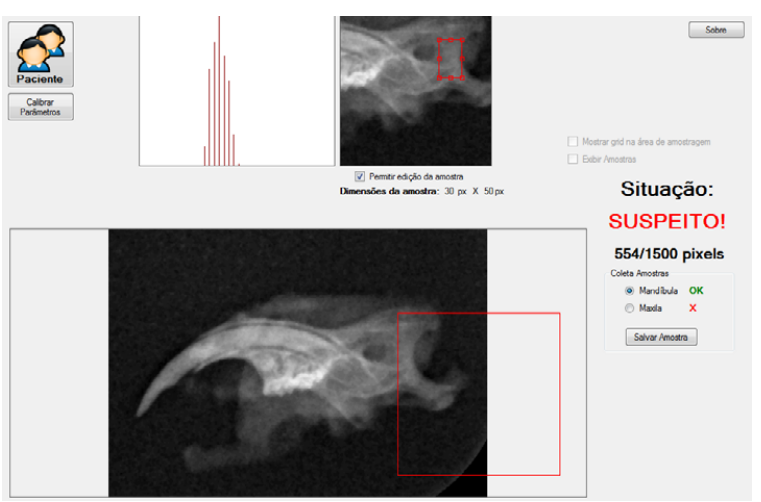

FIGURA $\mathbf{3} \cdot$ Interface do sistema para a contagem de pixels trabeculares em mandíbula

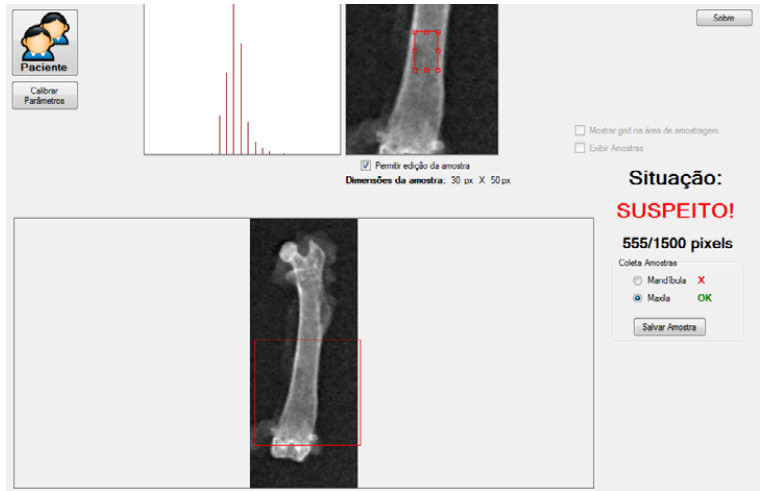

FIGURA 4 - Interface do sistema para a contagem de pixels trabeculares em diáfise femoral 


\section{Análise estatística}

Os dados de cada grupo foram tratados estatisticamente utilizando o programa GraphPad program Prism 5.0. O teste de normalidade foi aplicado para todos os dados, sendo que os dados da análise radiográfica foram analisados pelo teste ANOVA para os grupos ao longo tempo e a diferença foi obtida pelo método de comparação múltipla de Bonferroni. Todos os dados foram apresentados como \pm o erro padrão da média (SEM). O nível de significância foi de $5 \%(\mathrm{p}<0,05)$.

\section{Resultados}

\section{Resultados da análise do peso}

$\mathrm{Na}$ análise do peso não houve diferença estatística entre os grupos durante o período de 21 dias, houve somente no grupo VitD 28d, que corresponde a primeira semana após o término da suplementação de VitD, obtendo-se os seguintes valores médios em gramas: C inicial $(24,29)$; VitD inicial $(24,4)$; C7d (25,06); VitD7d (24,92); C14d (25,50); VitD14d (25,26); C21d $(26,13)$; VitD21D $(25,34)$; C28D $(26,26)$ e VitD28d $(36,01)$.

\section{Resultados da análise radiográfica}

Na mandíbula houve diferença estatística significante dos valores médios de pixels trabeculares no grupo suplementado com VitD em comparação ao controle nos períodos de 7 e 21 dias (Gráfico 2A). Entretanto, não houve um aumento dos valores dos pixels trabeculares no grupo suplementado com VitD ao longo do tempo.

Na extremidade longa do fêmur ou diáfise, houve diferença estatística significante no valor médio de pixels trabeculares no grupo suplementado comparado ao controle aos 7 dias (Gráfico 2B). Entretanto, não houve um aumento dos valores dos pixels trabeculares no grupo controle ao longo do tempo. Houve diminuição dos valores dos pixels trabeculares no grupo VitD ao longo do tempo (Tabela 1). 
A análise da região metafisária demonstrou que não houve diferença estatística na densidade óssea entre os grupos analisados (Gráfico 2C).

TABELA 1 - Valores médios de pixels trabeculares para as regiões da mandíbula e fêmur dos grupos controle e VitD em 7 e 21 dias

\begin{tabular}{llll}
\hline $\begin{array}{l}\text { Grupo/Pixels } \\
\text { trabeculares }\end{array}$ & Mandíbula & Fêmur (diáfise) & Fêmur (metáfise) \\
\hline $\mathrm{C} 7 \mathrm{~d}$ & $692,0( \pm 23,50)$ & $572,7( \pm 18,71)$ & $769,1( \pm 14,23)$ \\
\hline VitD7d & $805,3( \pm 19,98)$ & $723,0( \pm 23,83)$ & $768,1( \pm 9,61)$ \\
\hline C21d & $665,1( \pm 21,72)$ & $507,6( \pm 17,50)$ & $733,6( \pm 8,62)$ \\
\hline VitD21d & $800,0( \pm 19,66)$ & $620,2( \pm 16,20)$ & $750,7( \pm 8,64)$ \\
\hline Valor de $p$ & $p<0,0001 \star \star$ & $p<0,0001 \star \star$ & $p=0,05$
\end{tabular}

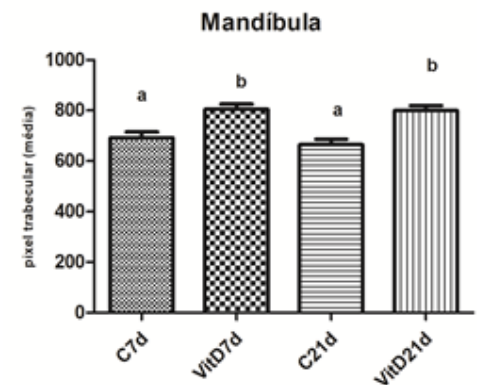

GRÁFICO 2A • Valores médios da densidade óssea de acordo com a contagem de pixels trabeculares comparando os grupos e seus respectivos períodos de cicatrização periimplantar da mandíbula. *Letra diferente signifıca diferença estatística

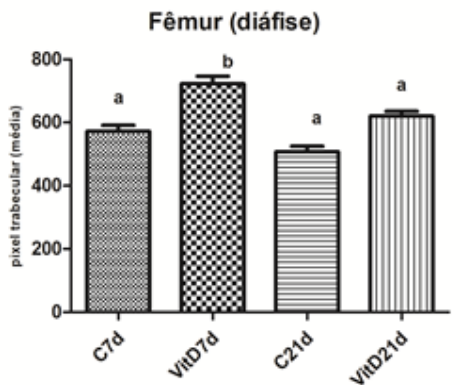

GRÁFICO 2B • Valores médios da densidade óssea de acordo com a contagem de pixels trabeculares comparando os grupos na região de diáfise femoral. *Letra diferente significa diferença estatística

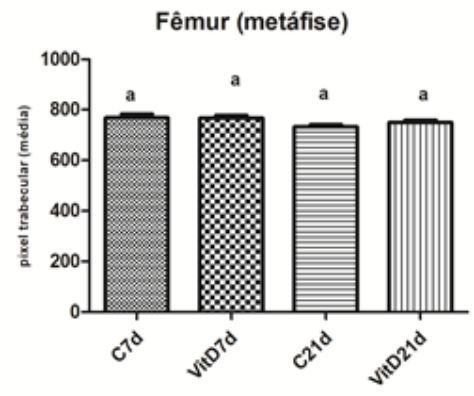

GRÁFICO 2C • Valores médios da densidade óssea de acordo com a contagem de pixels trabeculares comparando os grupos na região de metáfise femoral

\section{Discussão}

Esta pesquisa analisou a densidade óssea radiográfica do fêmur (diáfise e metáfise) e da mandíbula em camundongos que foram suplementados com vitamina D3 (VitD) e submetidos a colocação de implantes de titânio no corpo mandibular nos períodos de 7 e 21 dias. Sabe-se que a VitD influência no metabolismo do cálcio e fosfato para a manutenção e reparação do tecido 
ósseo, por este motivo o trabalho buscou avaliar a influência da VitD sobre as estruturas ósseas do fêmur e da mandíbula, devido ao fato de serem estruturas de origem mesenquimal e localização anatômica distintas. Entretanto, na prática clínica da Implantodontia, devido à inexistência do diagnóstico de alteração da densidade óssea mandibular, é solicitada a densitometria óssea do fêmur. Exame este, muitas vezes, necessário para o diagnóstico e planejamento na Implantodontia.

$\mathrm{Na}$ diáfise femoral houve diferença significativa na densidade óssea entre os grupos controle e VitD, principalmente, na comparação entre C7d vs VitD7d e C21d vs VitD21d, demonstrando ganhos de massa óssea pelo aumento quantitativo na contagem de pixels trabeculares. Estudos de análise radiográfica e microtomografia computadorizada ( $\mu \mathrm{TC}$ ) envolvendo a suplementação, deficiência de vitamina D3 ou associação com doenças crônicas e mutações genéticas demonstraram influência da Vit D na massa óssea, como o de Panda et al. ${ }^{24}$ (2004) que demonstraram por meio de um modelo de camundongo mutante em VDR e 1- $\alpha$-hidroxilase, que houve redução de massa óssea em fêmures no grupo com dieta pobre em cálcio, lactose e restrição de 1,25D. Triliana et al. ${ }^{25}$ (2016) demonstraram em linhagens de camundongos com VDR superexpresso que houve aumento de massa óssea através de análise histológica e $\mu \mathrm{TC}$.

$\mathrm{Na}$ análise mandibular houve aumento na densidade óssea entre os grupos e nos diferentes períodos de cicatrização, sendo mais acentuada entre C21d vs VitD21d. Porém, não há na literatura científica estudos in vivo que comparem a densidade óssea mandibular e femoral, o que dificultou a discussão ou correlação com os nossos achados radiográficos. Da mesma forma, não há estudos in vivo que avaliam a influência da suplementação de vitamina $\mathrm{D}$ nos ossos maxilares associados com implantes osseointegrados, porém alguns autores apresentaram estudos em que avaliaram a reparação óssea ao redor dos implantes de titânio no fêmur e que concordam com nossos resultados como 
no estudo de Wu et al. ${ }^{17}$ (2013) que investigaram o efeito da VitD associado a insulina sobre a osseointegração em implantes no fêmur de ratos e observaram por $\mu \mathrm{TC}$ que houve aumento de 1,6 vezes no volume ósseo ao redor implante comparado ao fêmur, bem como no estudo de Zhou et al. ${ }^{26}$ (2012) analisaram o efeito de $1,25 \mathrm{D}$ na osseointegração de implantes na tíbia de ratas osteoporóticas ovariectomizadas, e a análise em $\mu \mathrm{TC}$ revelou aumento considerável na espessura trabecular em 51,8\% em relação ao grupo não suplementado. Liu et al. ${ }^{27}$ (2014) avaliaram a influência da VitD sobre doença renal crônica (DRC) induzida por nefrectomia parcial e a análise radiográfica demostrou que o implante foi completamente envolvido por osso sem qualquer lacuna radiotranslúcida no grupo DRC suplementado comparado ao controle. Apesar da inexistência de estudos sobre a correlação da densidade óssea mandibular e femoral, nosso estudo identificou pela análise da contagem de pixels trabeculares que houve ganho de massa óssea mandibular e extremidade longa do fêmur (diáfise) no grupo suplementado com VitD.

$\mathrm{Na}$ análise sistêmica da VitD, observou-se aumento significativo dos níveis séricos de $25(\mathrm{OH})$ VD no grupo VitD7d, sendo que o mesmo grupo pela análise radiográfica teve o maior ganho em densidade óssea na mandíbula. Vários estudos indicaram que uma alta concentração sérica de 25-OHD pode ser benéfica para a saúde óssea ${ }^{28,29}$. Além disso, estudos demonstraram que doses alta de suplementação de VitD pode aumentar a densidade mineral óssea ${ }^{30,31}$. A densidade mineral óssea pode ser alterada na remodelação óssea, um processo contínuo da formação óssea ao longo da vida, de forma a manter a massa óssea e microestrutura de forma saudável ${ }^{32}$. Neste sentido, a quantidade de VDR e $25(\mathrm{OH}) \mathrm{VD}$ podem, também, desempenhar papel promotor ou supressor de atividade osteogênica ${ }^{33}$.

Os resultados deste estudo demostraram que a suplementação com VitD3 nos períodos de 7 e 21 dias, não apresentaram diferenças estatísticas na densidade óssea das estruturas 
metafisárias, quando comparadas ao grupo controle (não suplementado). Considerando que há diversos fatores e vias de sinalização que podem influenciar a remodelação óssea e não foram abordados nesse trabalho, acredita-se a dose ou o período de suplementação pode não ter sido suficiente para modificar as estruturas ${ }^{34}$.

Outro fator que pode ser considerado na discussão dos nossos resultados, se refere ao pico de massa óssea. Segundo a revisão de literatura de Stagi et al. ${ }^{35}$ (2013), o pico de massa óssea do esqueleto humano ainda não está definido, mas estima-se que seja aos 16-18 anos para fêmur, coluna e pescoço e de 35 anos para o crânio. Os animais deste estudo possuíam idade entre 12-16 semanas o que corresponde a idade adulta no ser humano. Da mesma forma, o pico da massa óssea em camundongos ainda não foi estabelecido, inclusive com variações na densidade óssea entre as espécies ${ }^{36}$.

Além disso, a VitD atua na absorção de cálcio através da ação de metabólito renal 1,25D sobre o intestino especialmente na puberdade, promovendo um aumento na absorção de cálcio, com consequente aumento da deposição mineral óssea ocorrendo em torno dos 16,7 anos ${ }^{37-39}$ e como demonstrado por Triliana et $a l{ }^{25}$ (2016) pode ocorrer aumento na densidade mineral óssea em metáfise e diáfise femoral em camundongos com superexpressão de VDR com o passar da idade.

Podemos citar a interferência dos ácidos graxos, pois durante 4 semanas ambos os grupos receberam óleo de girassol, demonstrando aumento de peso significativo no grupo experimento, pois o excesso de gordura pode interferir no aproveitamento metabólico ósseo da vitamina $\mathrm{D}^{40}$. Entretanto, o tipo de preparação da vitamina $\mathrm{D}$ (oleosa ou sólida) não parece influenciar na absorção de vitamina D. ${ }^{41}$ Além disso, a revisão da literatura de Nastri et al. ${ }^{42}$ (2020) demonstraram que o veículo utilizado para suplementação da vitamina $\mathrm{D}$ em animais não apresenta 
um padrão definido, da mesma forma encontrado nos produtos disponíveis comercialmente para uso em seres humanos.

Apesar dos achados radiográficos a pesquisa apresentou algumas limitações importantes no que diz respeito a falta de estudos da influência da VitD sobre o osso mandibular, pois o caráter exploratório do estudo acabou limitando os termos de revisão de literatura e de discussão de resultados com o de outros autores.

Outras pesquisas envolvendo diferentes metodologias de suplementação, aperfeiçoamento de técnicas cirúrgicas na mandíbula, análises histológicas e radiográficas complementadas às técnicas de imunohistoquímica e de quantificação gênica poderão esclarecer os questionamentos sobre a densidade óssea na odontologia.

\section{Conclusão}

Os resultados deste estudo indicaram um aumento na densidade óssea após a suplementação com vitamina D3, principalmente, ao redor do implante mandibular e na região de diáfise do fêmur. E, a avaliação radiográfica sugeriu uma relação positiva da densidade óssea da mandíbula e do fêmur nos grupos com e sem suplementação de VitD. Estudos a níveis microscópico e molecular seriam necessários para confirmar essa relação.

\section{Agradecimentos}

Ao Biotério da Faculdade de Odontologia de Bauru Universidade de São Paulo pela doação de camundongos da linhagem C57BL/6 (WT) que permitiu a realização deste estudo.

\section{Referências}

1 - Jones G, Strugnell SA, Deluca HF. Current understanding of the molecular actions of vitamin D. Physiol Rev. 1998;78(4):1193-1231.

2 - Sutton ALM, Macdonald PN. Vitamin D: more than a "bone-a-fide" hormone. Mol Endocrinol. 2003;17(5):777-791. 
3- Kelly J, Lin A, Wang CJ, Park S, Nishimura I. Vitamin D and bone physiology : demonstration of vitamin d deficiency in an implant osseointegration rat model. J Prosthodont. 2009;18(6):473-478.

4 - Alvim-Pereira F, Montes CC, Thomé G, Olandoski M, Trevillato PC. Analysis of association of clinical aspects and vitamin D receptor gene polymorphism with dental implant loss. Clin Oral Implants Res. 2008;19(8):786-795.

5 - Raisz LG, Trummel CL, Holick MF. 1,25-dihydroxycholecalciferol: a potent stimulator of bone resorption in tissue culture. Science. 1972;175(175):768-9.

6 - Suda T, Masuyama R, Bouillon R, Carmeliet G. Physiological functions of vitamin $\mathrm{D}$ : what we have learned from global and conditional VDR knockout mouse studies. Curr Opin Pharmacol. 2015;22:87-99.

7 - Bone D, Erben RG, Bromm S, Stangassinger M. Calcium in Osteopenic Ovariectomized Rats : Evidence for a Direct Anabolic Effect of 1 ,25-Dihydroxyvitamin. Endocrinol. 1998;139(10):4319-4328.

8 - Cao Y, Mori S, Mashiba T. 1 $\alpha, 25$-Dihydroxy-2 $\beta$ (3-hydroxypropoxy) vitamin D3 (ED-71) suppressed callus remodeling but did not interfere with fracture healing in rat femora. Bone. 2007;40(1):132-139.

9- Anderson PH, Atkins GJ, Turner AG, Kogawa M, Findlay DM, Morris HA. Vitamin D metabolism within bone cells: effects on bone structure and strength. Mol Cell Endocrinol. 2011;347(1-2):42-47.

10 - Deluca HF. The development of a bone- and parathyroid-specific analog of vitamin D: 2-methylene-19-Nor-(20S)-1a,25-dihydroxyvitamin D3. Bonekey Rep. 2014;514(514): 3-6.

11 - Lips P. Vitamin D physiology. Prog Biophys Mol Biol. 2006;92(1):4-8.

12 - Gannagé-yared MH, Chemali R, Yaacoub N, Halaby G. Hypovitaminosis D in a sunny country: relation to lifestyle and bone markers. J Bone Miner Res. 2000;15(9):1856-62.

13 - Anderson PH, Turner AG, Morris HA. Vitamin D actions to regulate calcium and skeletal homeostasis. Clin Biochemistry. 2012;45(12):880-886.

14 - Wezeman FH, Juknelis D, Himes R, Callaci JJ. Vitamin D and ibandronate prevent cancellous bone loss associated with binge alcohol treatment in male rats. Bone. 2007;41(4):639-45.

15 - Anderson PH, Sawyer RK, Moore AJ, May BK, O'Loughlin PD, Morris HA. Vitamin D depletion induces RANKL-mediated osteoclastogenesis and bone loss in a rodent model. J Bone Miner Res. 2008; 23(11):1789- 1797

16 - Shiizaki K, Hatamura I, Imazeki I, Moriguchi Y, Sakaguchi T. Improvement of impaired calcium and skeletal homeostasis in vitamin D receptor knockout mice by a high dose of calcitriol and maxacalcitol. Bone. 2009;45(5):964-971. 
17 - Wu Y, Yu T, Yang X, Li F, Ma L, Yang Y, et al. Vitamin D 3 and insulin combined treatment promotes titanium implant osseointegration in diabetes mellitus rats. Bone. 2013;52:1-8.

18 - Lam NN, Triliana R, Sawyer RK, Atkins GJ, Morris HA, O'Loughlin PD, et al. Vitamin D receptor overexpression in osteoblasts and osteocytes prevents bone loss during vitamin D-deficiency. J Steroid Biochem Mol Bio. 2014;144(pt.A):128-31.

19 - Naja RP, Dardenne O, Arabian A, Arnaud S. Chondrocyte-Specific Modulation of Cyp27b1. Endojournals. 2014;150(9):4024-4032.

20 - Anderson PH, Lam NN, Turner AG, Davey RA, Kogawa M, Atkins GJ, et al.The pleiotropic effects of vitamin D in bone. J Steroid Biochem Mol Bio. 2013;136:190-194.

21 - Piccolotto A, Palczewski RH, Santa Catarina A, Togashi AY. Desenvolvimento de software para a avaliação para avaliação da densidade óssea por meio da análise de radiografias odontológicas digitais. Braz Oral Res. 2014;28:469.

22 - Palczewski RH, Luize DS, Catarina AS, Verde LHCV, Togashi AY. Padronização da densidade óssea em radiografias odontológicas através da contagem de pixels trabeculares pelo software B $\mu$ A-DDX. Braz Oral Res. 2015;29:274.

23 - Togashi AY, Catarina AC, Batistussi LR, Coelho G. Bone Microarchitecture by Dentistry Digital X-Ray (B $\mu$ A- DDX) Software: A Pilot Study of the Analysis of Bone Density using Digital Dental X-Rays. Curr Res Dent. 2015;28(6):18-26.

24 - Panda DK, Miao D, Bolivar I, Li J, Huo R, Hendy GN, et al. Inactivation of the 25-Hydroxyvitamin D 1】-Hydroxylase and Vitamin D Receptor Demonstrates Independent and Interdependent Effects of Calcium and Vitamin D on Skeletal and Mineral Homeostasis. J Biol Chem. 2004;279(16):16754-16766.

25 - Triliana R, Lam NN, Sawyer RK, Atkins GJ, Morris HA, Anderson PH. Skeletal characterization of an osteoblast-specific vitamin $D$ receptor transgenic (ObVDR-B6) mouse model. J Steroid Biochem Mol Biol. 2016; 164:331-336.

26- Zhou C, Li Y, Wang X, Shui X. 1, 25Dihydroxy vitamin D 3 improves titanium implant osseointegration in osteoporotic rats. Oral Maxillofac Surg. 2012;114(5): 174-178.

27 - Liu W, Zhang S, Zhao D, Zou H, Sun N, Liang X, et al. Vitamin D supplementation enhances the fixation of titanium implants in chronic kidney disease mice. PloS One. 2014;9(4):e95689.

28 - Bischoff-Ferrari HA, Dietrich T, Orav EJ, Dawson-Hughes B. Positive association between 25-hydroxyvitamin D levels and bone mineral density: a population-based study of younger and older adults. Am J Med. 2004;116:634-639. 
29 - Heaney RP. The vitamin D requirement in health and disease. J Steroid Biochem Mol Biol. 2005, 97(1-2):13-19.

30 - Dawson-Hughes B, Harris SS, Krall EA, Dallal GE. Effect of calcium and vitamin D supplementation on bone density in men and women 65 years of age or older. New England J Med. 1997; 337(10): 670-676.

31 - Hildebolt CF, Pilgram TK, Dotson M, Armamento-Villareal R, Hauser $\mathrm{J}$, Cohen $\mathrm{S}$, et al. Estrogen and/or calcium plus vitamin D increase mandibular bone mass. J Periodontol. 2004;75(6):811-816.

32 - Hadjidakis DJ, Androulakis II. Bone remodeling. Annals of the New York Academy Sciences. 2006;1092(1):385-396.

33 - Yang D, Anderson PH, Wijenayaka AR, Barratt KR, Triliana R, Stapledon CJM, et al. Both ligand and VDR expression levels critically determine the effect of $1 \mathbb{Q}, 25$-dihydroxyvitamin- $\mathrm{D}_{3}$ on osteoblast differentiation. J Steroid Biochem Mol Biol. 2018;177:83-90.

34 - Akhavan A, Noroozi Z, Shafiei AA, Haghighat A, Jahanshahi GR, Mousavi SB. The effect of vitamin D supplementation on bone formation around titanium implants in diabetic rats. Dent Res J. 2012; 9(5):582-587.

35 - Stagi S, Cavalli L, Iurato C, Seminara S, Brandi ML, Martino M. Bone metabolism in children and adolescents: main characteristics of the determinants of peak bone mass. Clin Cases Miner Bone Metab. 2013;10(3):172-9.

36 - Akhter MP, Iwaniec UT, Covey MA, Cullen DM, Kimmel DB, Recker RR. Genetic Variations in Bone Density, Histomorphometry, and Strength in Mice. Calcif Tissue Int. 2000;67(4):337-44.

37 - Marcus R. Endogenous and nutritional factors affecting bone. Bone. 1996;18(1):11-13.

38 - Winzenberg TM, Shaw K, Fryer J, Jones G. Calcium supplementation for improving bone mineral density in children (Review). The Cochrane Library. 2010; 127(4): CD005119.

39 - Winzenberg T, Powell S, Shaw K A, Jones G. Effects of vitamin D supplementation on bone density in healthy children: systematic review and meta-analysis. BMJ (Clinical research). 2011; 342: c7254.

40 - Wang Y, Buckendahl P, Sharma K, Miller JW, Shapses SA. Expression of vitamin D hydroxylases and bone quality in obese mice consuming saturated or monounsaturated enriched high-fat diets. Nutr Res. 2018; 60:106-15.

41 - Mulligan GB, Licata A. Taking vitamin D with the largest meal improves absorption and results in higher serum levels of 25-hydroxyvitamin D. J Bone Miner Res. 2010;25(4):928-30.

42 - Nastri L, Moretti A, Migliaccio S, Paoletta M, Annunziata M, Liguori S, et al. Do dietary supplements and nutraceuticals have effects on dental implant osseointegration? A scoping review. Nutrients. 2020;12(268):1-16. 


\title{
Bone density evaluation of the mandible and femur of mice supplemented with vitamin D
}

\begin{abstract}
Objective: This experimental study was conducted to evaluate the effect of vitamin D3 (VitD) supplementation on the bone density of the mice femur and jaw. Material and Methods: Mice C57BL/6 were divided into two groups: 1) control group and 2) VitD group - systemic administration of VitD using vitamin D3 gavage at a concentration of 10,000 IU for week. After 4 weeks of VitD administration was performed titanium implants placement in the lateral region of the mandible. After 7 and 21 days of implants installation, digital periapical radiographs of the regions of femoral and of jaw were analyzed by BmA-DDX program, which were evaluated the trabecular pixels counting. For the statistical analysis were applied Anova and Bonferroni multiple correlation tests. Results: The results of radiographic analyses showed that the jaw was increased in bone density in the supplemented group compared to the control group $(\mathrm{p}<0.05)$, there were no differences in the group during the time. In the metaphyseal region of the femur there was no difference between control and VitD groups during the time, however, in the diaphyseal region noticed an increase of the trabecular pixels counting in the VitD group compared to the control group $(p=0.001)$. Conclusions: It can be suggested that supplementation with vitamin D3 indicated an increase in bone density in the jaw around the implant and femoral diaphysis by the radiographic analysis.
\end{abstract}

KEYWORDS: Mice. Bone Density. Radiography, Dental. Dietary Supplements. Vitamin D.

\section{Como citar este artigo}

Palczewski RH, Luize DS, Catarina AS, Togashi AY. Avaliação da densidade óssea da mandíbula e fêmur de camundongos suplementados com vitamina D. Rev Odontol Bras Central 2021; 30(89): 273-289. DOI: 10.36065/robrac.v30i89.1442 